\title{
Functional Analysis of Circadian Pacemaker Neurons in Drosophila melanogaster
}

\author{
Dirk Rieger, ${ }^{1}$ Orie Thomas Shafer, ${ }^{2}$ Kenji Tomioka, ${ }^{3}$ and Charlotte Helfrich-Förster ${ }^{1}$ \\ ${ }^{1}$ University of Regensburg, Institute of Zoology, 93040 Regensburg, Germany, ${ }^{2}$ Department of Anatomy and Neurobiology, Washington University School \\ of Medicine, St. Louis, Missouri 63110, and ${ }^{3}$ Department of Biology, Faculty of Science, Okayama University, Okayama 700-8530, Japan
}

The molecular mechanisms of circadian rhythms are well known, but how multiple clocks within one organism generate a structured rhythmic output remains a mystery. Many animals show bimodal activity rhythms with morning (M) and evening (E) activity bouts. One long-standing model assumes that two mutually coupled oscillators underlie these bouts and show different sensitivities to light. Three groups of lateral neurons (LN) and three groups of dorsal neurons govern behavioral rhythmicity of Drosophila. Recent data suggest that two groups of the LN (the ventral subset of the small LN cells and the dorsal subset of LN cells) are plausible candidates for the M and E oscillator, respectively. We provide evidence that these neuronal groups respond differently to light and can be completely desynchronized from one another by constant light, leading to two activity components that free-run with different periods. As expected, a long-period component started from the E activity bout. However, a short-period component originated not exclusively from the morning peak but more prominently from the evening peak. This reveals an interesting deviation from the original Pittendrigh and Daan (1976) model and suggests that a subgroup of the ventral subset of the small LN acts as "main" oscillator controlling M and E activity bouts in Drosophila.

Key words: period; timeless; dual oscillators; internal desynchronization; constant light; cryptochrome

\section{Introduction}

Daily biological rhythms are governed by inherent timekeeping mechanisms, called circadian clocks. Such clocks reside in discrete sites of the brain and consist of multiple autonomous single-cell oscillators (Helfrich-Förster, 2004). Within each neuron, interacting transcriptional and translational molecular feedback loops as well as ionic signaling pathways constitute the oscillatory mechanism of the clock (Nitabach et al., 2002, 2005; Hardin, 2004). It is not understood how individual pacemaker neurons interact to drive behavioral rhythmicity. The longstanding model of Pittendrigh and Daan (1976) assumes that the clock consists of two groups of oscillators with different responsiveness to light, one governing the morning $(\mathrm{M})$ and the other the evening (E) activity of the animal. Typical $\mathrm{M}$ and $\mathrm{E}$ activity bouts are present in animals ranging from insects to mammals and suggest that the two-oscillatory model is generally valid (Aschoff, 1966; Helfrich-Förster, 2001; Dunlap et al., 2003). Recently, Stoleru et al. (2004) and Grima et al. (2004) showed that M and $\mathrm{E}$ bouts could be eliminated or reinstated by manipulating different circadian pacemaker neurons in Drosophila melanogaster. This work suggested that the ventral $\left(\mathrm{LN}_{\mathrm{v}}\right)$ and dorsal

Received March 30, 2005; revised Dec. 22, 2005; accepted Dec. 23, 2005.

This work was supported by Deutsche Forschungs Gemeinschaft Grant Fo207-9-1 (C.H.-F.). We thank R. Stanewsky for providing the $\mathrm{Cry}^{b}$ mutants and the PER-antiserum, A. Hofbauer for the nb33-monoclonal antibody, M. Rosbash for the TIM-antiserum, A. Hofbauer and R. Stanewsky for comments on a previous version of this manuscript, as well as members of our laboratories for fruitful discussions and suggestions.

Correspondence should be addressed to Charlotte Helfrich-Förster, University of Regensburg, Institute of Zoology, Universitaetsstraße 31, 93040 Regensburg, Germany. E-mail: charlotte.foerster@biologie.uni-regensburg./.de.

DOI:10.1523/JNEUROSCI.1234-05.2006

Copyright $\odot 2006$ Society for Neuroscience $\quad 0270-6474 / 06 / 262531-13 \$ 15.00 / 0$
$\left(\mathrm{LN}_{\mathrm{d}}\right)$ subsets of the lateral neurons (see Fig. 1) are the neuronal substrates for the $\mathrm{M}$ and $\mathrm{E}$ oscillators. It is not known whether these two oscillators respond differently to light (Schwartz, 2004).

The particular power of the two-oscillator model is that it explains observed adaptations to seasonal changes in day length. The model predicts that the $\mathrm{M}$ oscillator will shorten and the $\mathrm{E}$ oscillator will lengthen its period when exposed to extended constant light (LL) (Pittendrigh and Daan, 1976; Daan et al., 2001). As a consequence, the $\mathrm{M}$ activity occurs earlier and the E activity occurs later in long summer days, helping day-active animals avoid the midday heat (Majercak et al., 1999). The model also predicts that the $\mathrm{M}$ oscillator will free-run with short period and the $\mathrm{E}$ oscillator with long period when animals are placed in constant light. However, such internal desynchronization between oscillators does not occur, because high-intensity constant light usually results in arrhythmicity (Aschoff, 1979; Konopka et al., 1989). In D. melanogaster, the clock protein Timeless (TIM) is permanently degraded during light-induced interaction with Cryptochrome (CRY), leading finally to the arrest of the clock (Ceriani et al., 1999; Emery et al., 2000; Rosato et al., 2001; Busza et al., 2004). Without functional CRY, this does not happen. Indeed, internal desynchronization into two free-running components (one with a short period and the other with a long period) was described recently for $c r y^{b}$ mutants under constantlight conditions (Yoshii et al., 2004). In that study, behavioral rhythm dissociation was associated with a dissociation of Period (PER) expression between ventrally and dorsally located pacemaker neurons, but the authors could not distinguish between the $\mathrm{LN}_{\mathrm{v}}$ and $\mathrm{LN}_{\mathrm{d}}$. The present study aims to analyze the molecular 


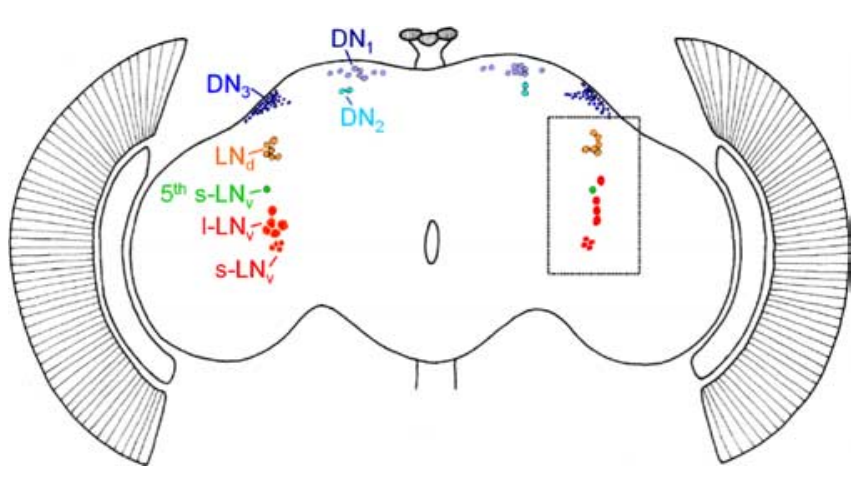

Figure 1. Circadian pacemaker neurons in the brain of the fruit fly. The three clusters of dorsal neurons $\left(\mathrm{DN}_{1}, \mathrm{DN}_{2}\right.$, and $\mathrm{DN}_{3}$ cells) are shown in blue colors, the three clusters of lateral neurons are shown in red (PDF-positive $s-L_{v}$ and I- $L N_{v}$ cells) or orange ( $\mathrm{LN}_{d}$ cells), and the PDF-negative 5th $s-\mathrm{LN}_{v}$ cell is depicted in green. The square in the right brain hemisphere indicates the area of the sections shown in Figures $4 A-D, 6$, and 7.

state of all clock gene-expressing neurons during behavioral rhythm dissociation to test the Pittendrigh-Daan model and refine the neuronal substrates of the $\mathrm{E}$ and $\mathrm{M}$ oscillators.

\section{Materials and Methods}

Fly strains and recording of locomotor activity. We used red-eyed $c r y^{b}$ mutants $\left(+/+\right.$ cry $^{b}$ rec $\left.^{s}\right)$ (Stanewsky et al., 1998), cli $^{\text {eya }} ;$ cry $^{b}$ double mutants (Rieger et al., 2003), and the wild-type strain Canton S for the present experiments. The main difference between $c r y^{b}$ mutants and cli ${ }^{\text {eya }} ;$ cry $^{b}$ double mutants is the absence of the compound eyes in the cli $^{\text {eya }} ;$ cry $^{b}$ flies. Flies were raised on cornmeal medium at $25^{\circ} \mathrm{C}$ under a $12 \mathrm{~h}$ light/dark cycle (LD). At the age of 1-3 d, individual male flies were transferred into the recording chambers. Locomotor activity was recorded photoelectrically at $20^{\circ} \mathrm{C}$ as described previously (HelfrichFörster, 1998). Halogen photooptic lamps (Xenophot; Osram) served as a light source, and intensity was adjusted to $500 \mu \mathrm{W} / \mathrm{cm}^{2}$ with a dimmer. Activity was recorded for up to $7 \mathrm{~d}$ under LD, and then the flies were transferred to LL of the same intensity. To better see the rise of the M activity bout in $c r y^{b}$ mutants, which usually occurs before lights on but was essentially suppressed by darkness in these mutants, one group of $c r y^{b}$ flies was exposed to weak light $\left(0.25 \mu \mathrm{W} / \mathrm{cm}^{2}\right.$ equaling full-moon light) during the dark phase of their LD cycle. Afterward, they were transferred to LL of the same light intensity $\left(500 \mu \mathrm{W} / \mathrm{cm}^{2}\right)$ as the first group. Wild-type Canton $\mathrm{S}$ flies were recorded under LL conditions of moon light intensity $\left(0.25 \mu \mathrm{W} / \mathrm{cm}^{2}\right)$ additionally to that of $500 \mu \mathrm{W} /$ $\mathrm{cm}^{2}$, because all flies became immediately arrhythmic at the high luminance.

Data analysis. The raw data were displayed as actograms (double plots) to judge the activity pattern, and the periods under LL were determined by the Sokolove-Bushell periodogram analysis (program El Temps; DiezNoguera, Barcelona, Spain). To reveal the behavior of all $c r y^{b}$ flies on days 1,5 , and 11 in LL, average \pm SE activity profiles were calculated for these single days as described previously (Helfrich-Förster, 2000).

Immunohistochemistry and quantification of staining intensity. Brains of wild-type and $c r y^{b}$ mutants flies were examined with respect to the position of the different circadian pacemaker groups (Fig. 1). For that purpose, 10 wild-type and $10 \mathrm{cry} \mathrm{b}^{b}$ mutants were collected $1 \mathrm{~h}$ before lights on of LD because, at that time, TIM and PER levels are close to their peak levels.

To gauge the extent of neuronal desynchronization, 10 wild-type and $10 c r y^{b}$ flies were collected at four different time points in LL (see Fig. 3, a, b on the first day in LL and c, d on the fifth day in LL). As additional controls, 10 eyeless $\mathrm{cli}^{\text {eya }} ; \mathrm{cry}^{b}$ flies were collected at their activity minimum and maximum on the fifth day in LL. At the different collection times in LL, flies were quickly killed by submersion in $4 \%$ freshly prepared paraformaldehyde in phosphate buffer (PB) with $0.5 \%$ Triton $\mathrm{X}$-100. After $2 \mathrm{~h}$ fixation, the flies were rinsed three times for $15 \mathrm{~min}$ in $\mathrm{PB}$, and their brains were dissected as whole mounts. After blocking in
5\% normal goat serum overnight, triple immunostainings were performed on the whole-mount brains with a rabbit anti-PER serum [diluted 1:1000 (Stanewsky et al., 1997)], a rat anti-TIM serum [diluted 1:1000 (Kaneko et al., 1997)], and the monoclonal mouse antibody nb33 (diluted 1:100). The latter recognizes the neuropeptide pigmentdispersing factor (PDF)-positive neurons (Veleri et al., 2003). Antibody labeling was performed for $48 \mathrm{~h}$ at $4^{\circ} \mathrm{C}$. After rinsing five times in $\mathrm{PB}$ $(0.5 \%$ Triton X-100), secondary fluorescence-conjugated antibodies were applied overnight: Alexa Fluor 488 (goat anti-rabbit), Alexa Fluor 568 (goat anti-rat), and Alexa Fluor 647 (goat anti-mouse), all diluted 1:200 (Invitrogen, Carlsbad, CA). Triple-labeling (green channel, PER; red channel, TIM; infrared channel converted to blue, PDF) was visualized by laser-scanning confocal microscopy (LSM 510 META; Zeiss, Oberkochen, Germany). To exclude bleed through, we used sequential scans of the three laser lines. Images presented in figures are overlays of several confocal stacks.

After discriminating between the different neurons on the overlays, scoring of staining intensities was performed on single optical sections that contained the nucleus for each neuron separately. For that purpose, the green (PER) and red (TIM) confocal channels were separately converted into grayscale. The grayscale pictures were imported into the program NIH Image J (version 1.33u; Wayne Rasband, freely available at http://rsb.info.nih.gov/ij/). For each neuron, mean pixel intensity of PER or TIM staining was measured for either the cytoplasm or the nucleus depending on which compartment was more strongly stained. Only subset 3 of the dorsal neurons $\left(\mathrm{DN}_{3}\right)$ were scored as an entire group (using the magic wand in the plug-in Yawi 2D) without discriminating between nuclear and cytoplasmic PER and TIM expression, because these cells were too small and too numerous to be scored individually. Grayscale units ranged between 0 (black) and 255 (white). A mean staining intensity was calculated from all neurons within one group for each hemisphere separately. Within the $\mathrm{LN}_{\mathrm{d}}$, one neuron was consistently more strongly stained than the others. The staining intensity of this neuron was not averaged with the remaining cells of the group but was treated separately as the "extra $\mathrm{LN}_{\mathrm{d}}$." A background staining level was measured in the surrounding field of each neuronal group and subtracted from the mean pixel intensities measured for the cells. A staining index for each cell group was calculated by multiplying the staining intensity (minus background) with the number of stained cells divided by the maximum number of stained cells within this specific cluster. The maximum number of cells for the different cell clusters was as follows: PDF-positive s-LN $\mathrm{LN}_{\mathrm{v}}, 4$; PDF-negative small (s) $\mathrm{LN}_{\mathrm{v}}, 1$; large (1) $\mathrm{LN}_{\mathrm{v}}, 5$; extra $\mathrm{LN}_{\mathrm{d}}, 1$; remaining $\mathrm{LN}_{\mathrm{d}}, 6 ; \mathrm{DN}_{1}, 17 ; \mathrm{DN}_{2}, 2$; and $\mathrm{DN}_{3}, 40$.

Statistics. Staining indices were tested for significant influences of strain and time point using two-way ANOVAs. A subsequent post hoc test with Bonferroni's adjustment was applied for pairwise comparisons of staining indices (Systat 10; SPSS, Chicago, IL). Values were regarded as significantly different at $p<0.05$.

\section{Results}

\section{Behavioral rhythms}

The activity rhythm of 20 wild-type flies, $40 \mathrm{cry}{ }^{b}$ mutants, and 33 cli $^{\text {eya }} ;$ cry $^{b}$ double mutants was recorded for $7 \mathrm{~d}$ under LD and subsequently for 3 weeks under LL (light intensity, $500 \mu \mathrm{W} /$ $\mathrm{cm}^{2}$ ). Under LD, all flies showed the typical bimodal activity pattern consisting of $\mathrm{M}$ and $\mathrm{E}$ activity bouts (Figs. 2, 3). Consistent with previous reports, the $\mathrm{M}$ activity bout was weaker than the E activity bout. After transfer into LL, all wild-type flies became immediately arrhythmic (Fig. 2A), whereas the cli $^{\text {eya }}$; $c r y^{b}$ flies remained rhythmic and free-ran with a period close to $24 \mathrm{~h}$ (Fig. 2E, Table 1) (see also below). In the majority of $c r y^{b}$ single mutants, the $M$ activity bout became invisible immediately after transfer into LL (Fig. 3). Thus, the activity changed from bimodal to unimodal with one major activity bout corresponding to the $\mathrm{E}$ peak. The same behavior is typical for wild-type flies after transfer into constant darkness (DD), but this does not mean that the putative $\mathrm{M}$ oscillator lost its activity (see Fig. 9, Table 3) (cf. 


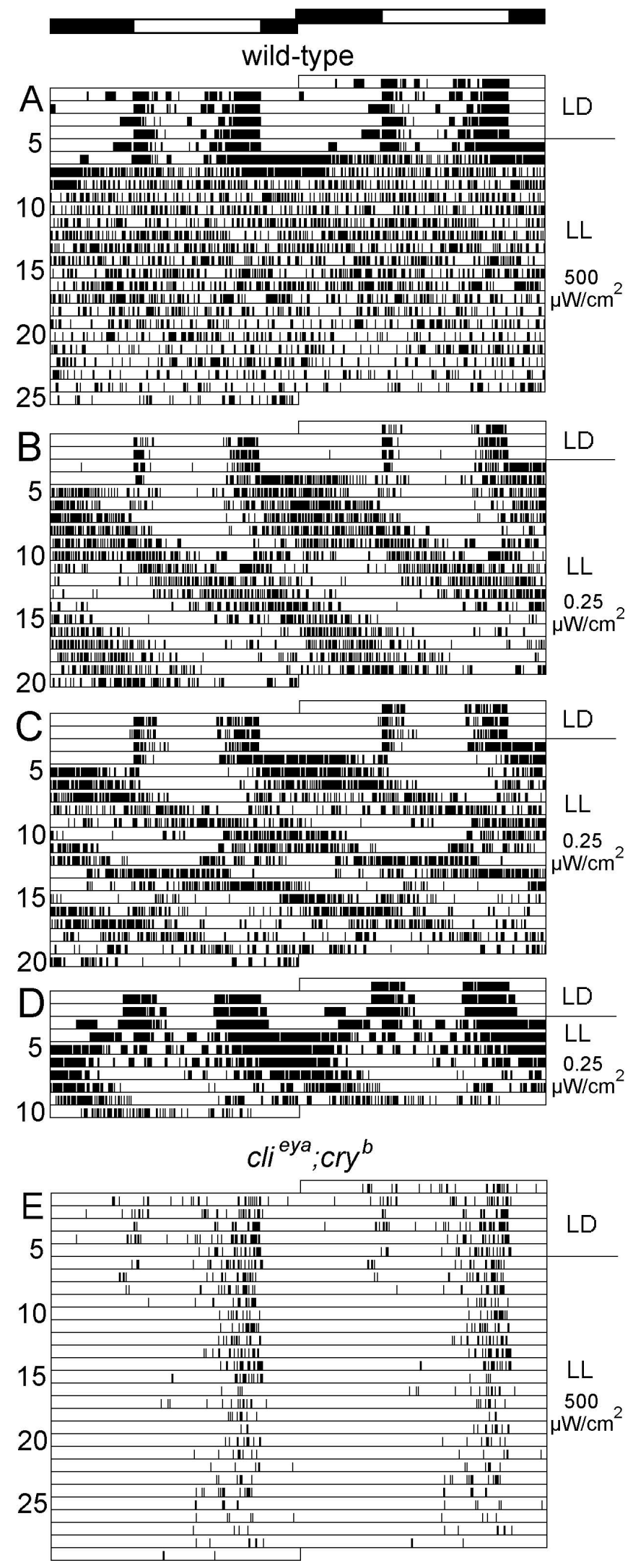

Figure 2. Constant dim light induces arrhythmicity and/or desynchronization in wild-type flies. Actograms of four wild-type flies $(\boldsymbol{A}-\boldsymbol{D})$ and $\mathrm{Cl}^{\text {eya }}{ }^{\text {; }} \mathrm{cry}^{b}$ mutants $(\boldsymbol{E})$ are shown that were recorded under an $L D$ cycle and subsequently under $L L$ conditions. The light program is indicated as white and black bars on top. The actograms are shown as double plot to better see the activity pattern under LL. During LD, light intensity was $500 \mu \mathrm{W} / \mathrm{cm}^{2}$ for all flies; during $L L$, light intensity was kept at $500 \mu \mathrm{W} / \mathrm{cm}^{2}$ for the clieya ; ${ }^{2} y^{b}$ mutant $(\boldsymbol{E})$ and the wild-type fly $(\boldsymbol{A})$;
Helfrich-Förster, 2001). For sake of clarity, we will now concentrate on the clearly visible $\mathrm{E}$ activity bout and refer to the $\mathrm{M}$ activity bout later. After a few days in LL, the E activity bout showed internal desynchronization into two activity components with short and long periods, respectively (Fig. 3). The frequency of internal desynchronization was found previously to be positively correlated with the light intensity, and the period of the short component became shorter with increasing light intensity and that of the long component became longer (Yoshii et al., 2004). Both findings indicate that internal desynchronization gradually increases with light intensity. In our experiment, all 40 flies showed internal desynchronization, with the short component having a period of $22.5 \mathrm{~h}$ and the long component a period of $25.2 \mathrm{~h}$ (Table 1). These coincide exactly with the periods observed by Yoshii et al. (2004) at the relevant light intensity. On the fifth day in LL, both components were $12 \mathrm{~h}$ out-of-phase with each other, and, after $11 \mathrm{~d}$, they were in-phase again (Fig. 3). This behavior had a very similar time course in all flies, as can be seen in the average activity profile of all 40 flies on days 1, 5, and 11 (Fig. 3). After having met on day 11, both components separated again (full crossing over) in half of the flies; in the other half, the components remained coupled and kept an intermediate period (23.5 h) (Table 1). The intermediate period was clearly closer to the period of the previous short component than to that of the longer component.

The eyeless $\mathrm{cli}^{\text {eya }}$; $\mathrm{cry}^{b}$ flies were tested to identify the photoreceptors responsible for the observed period lengthening and shortening under LL. The compound eyes are the most likely candidates because these are necessary for the adequate timing of $\mathrm{M}$ and $\mathrm{E}$ activity bouts in long summer days and short winter days (Rieger et al., 2003). As discussed above, this is a central task of M and $\mathrm{E}$ oscillators. Indeed, none of the $16 \mathrm{cli}^{e y a} ; \mathrm{cry}^{b}$ double mutants showed internal desynchronization, and all free-ran with a wild-type-like period (Fig. 2E, Table 1). This indicates that the compound eyes are the photoreceptors that transmit the light information to the putative $\mathrm{M}$ and $\mathrm{E}$ oscillators, provoking a period shortening in the former and a period lengthening in the latter.

To ensure that the observed internal desynchronization is not a peculiarity of $c r y^{b}$ mutants, we also studied the behavior of 23 wild-type flies under LL conditions of very-low-light intensity $\left(0.25 \mu \mathrm{W} / \mathrm{cm}^{2}\right)$. Under these conditions, only one fly became arrhythmic, seven flies free-ran with a rather long period $(\sim 27$ $\mathrm{h}$ ), and 15 flies showed two free-running periods as revealed by periodogram analysis, one with a mean of $23.7 \mathrm{~h}$ and the second with $28.2 \mathrm{~h}$ (Fig. $2 B-D$, Table 1 ). The shorter period component was not as clear as in $c r y^{b}$ mutants, but it could be seen in each actogram for at least $3 \mathrm{~d}$ (Fig. $2 \mathrm{~B}$ ). We conclude that the ability to show internal desynchronization into two activity components during light is a general feature of the locomotor rhythm of $D$. melanogaster. As for $c r y^{b}$ mutants, half of the wild-type flies showed full crossing over of both activity components under low light (Fig. 2C), whereas in the other half, the components coupled

\section{$\leftarrow$}

for the other wild-type flies, light intensity was reduced to $0.25 \mu \mathrm{W} / \mathrm{cm}^{2}$. Under $500 \mu \mathrm{W} / \mathrm{cm}^{2}$ light, the wild-type fly became arrhythmic immediately after transfer into $\mathrm{LL}(\boldsymbol{A})$, whereas the cli $^{\text {eya }}$; $r r^{b}$ mutant remained rhythmic $(\boldsymbol{E})$. At $0.25 \mu \mathrm{W} / \mathrm{cm}^{2}$, the wild-type flies showed internal desynchronization into two free-running components, one with a longer period and the other with a shorter period (see Table 1). Long and short components stayed together after the first cross-over in the fly shown in $\boldsymbol{B}$, whereas they showed full cross-over for two times in the fly shown in $\boldsymbol{C}$. $\operatorname{Bn}$ and $\boldsymbol{D}$, the short-period component appears to originate from the morning peak and the long-period component from the evening peak. 
and continued with an intermediate period (Fig. 2B, Table 1). Note that one fly showed a very prominent $M$ activity bout under LD (Fig. 2D). In this fly, the shortperiod component appeared to originate from the $M$ activity bout. Unfortunately, this fly died on day 10, so we could not further observe its behavior.

\section{Characterization of the different groups} of clock neurons

D. melanogaster possesses six groups of circadian pacemaker neurons: three groups of lateral neurons (the $s-\mathrm{LN}_{\mathrm{v}}$, l-LN $\mathrm{v}_{\mathrm{v}}$, and $\mathrm{LN}_{\mathrm{d}}$ cells) and three groups of dorsal neurons (the $\mathrm{DN}_{1}, \mathrm{DN}_{2}$, and $\mathrm{DN}_{3}$ cells) (Fig. 1). The $s-\mathrm{LN}_{\mathrm{v}}$ cluster can be further divided into four cells that express the PDF and in one cell that is PDF negative and known as 5 th s- $\mathrm{LN}_{\mathrm{v}}$ (Kaneko et al., 1997).

The first aim was to distinguish these neurons unequivocally from each other as well as to discriminate cytoplasmic from nuclear PER and TIM staining. The latter point seems trivial, but we found these proteins frequently located close to the nuclear membrane (Fig. 4) (and below),

making it difficult to decide between nuclear and cytoplasmic staining, especially in small neurons. Generally, we defined a protein location as nuclear if substantial staining was also found in more central parts of the nucleus and as cytoplasmic if no staining was visible in these places. To identify the individual clock neurons, we performed triple immunostainings with antibodies against the clock proteins PER and TIM and against the neuropeptide PDF at the time at which PER and TIM were close to peak levels ( $1 \mathrm{~h}$ before lights on in LD). To ensure that the secondary antibodies from rat and mouse do not show any crossreaction, we applied both secondary antisera also to brains that were either single labeled with only mouse anti-nb33 or only rat anti-TIM. We found no cross-reaction of the goat anti-mouse antibody with the rat anti-TIM, but we detected a weak crossreaction of the anti-rat secondary antibody with mouse antinb33. This cross-reaction was restricted to the cytoplasm of the l- $\mathrm{LN}_{\mathrm{v}}$, which contains a very large amount of PDF and was consequently very strongly labeled by the mouse anti-nb33. All other PDF-positive structures involving the strongly labeled arborizations arising from the $1-\mathrm{LN}_{\mathrm{v}}$ cells, as well as the s- $\mathrm{LN}_{\mathrm{v}}$ with their arborizations were not double labeled by the anti-rat secondary antibody. We conclude that the secondary antibodies are suffi- ciently specific for our needs, but we excluded the observed TIM staining in the cytoplasm of the $1-\mathrm{LN}_{\mathrm{v}}$ from additional analysis.

The anti-PDF labeling was necessary to distinguish the PDFpositive s- $\mathrm{LN}_{\mathrm{v}}$ and l-LN $\mathrm{L}_{\mathrm{v}}$ cells (Helfrich-Förster, 1995; Renn et al., 1999) from the $\mathrm{LN}_{\mathrm{d}}$ and the 5 th PDF-negative $s-\mathrm{LN}_{\mathrm{v}}$ cell (Fig. 1). The 5 th $\mathrm{s}-\mathrm{LN}_{\mathrm{v}}$ cell has only been described in larvae, because it was easily discerned from the few other larval clock neurons (Kaneko et al., 1997). During metamorphosis, glia cells start to express the clock proteins, and, because many PER-positive glia cells are found in close vicinity to the LN cells, it was hard to discern the 5th s- $\mathrm{LN}_{\mathrm{v}}$ among them in adults. Interestingly, we found only weak PER and TIM labeling in glia cells, and, as a consequence, we could unequivocally detect one PER-TIMpositive, but PDF-negative, neuron among the $\mathrm{LN}_{\mathrm{v}}$ cells. We regarded this cell as the 5th PDF-negative $s-\mathrm{LN}_{\mathrm{v}}$ cell. This neuron was not located among the four PDF-positive s- $\mathrm{LN}_{\mathrm{v}}$ cells but rather was among the more anteriorly located four to five PDFpositive l- $\mathrm{LN}_{\mathrm{v}}$ cells (Fig. $4 A-C$ ). Depending on the position of the $1-\mathrm{LN}_{\mathrm{v}}$ cells in the dorsoventral axis, the 5 th $\mathrm{s}-\mathrm{LN}_{\mathrm{v}}$ was located among them (Fig. $4 H-K$ ), dorsally to them, or slightly ventral to them (Table 2).

The l- $\mathrm{LN}_{\mathrm{v}}$ were the cells with the most variable position. In

Table 1. Rhythmic activity patterns under LL

\begin{tabular}{llllllllll}
\hline Genotype/condition & $n$ & Arrhythmicity & $\begin{array}{l}\text { 1 rhythmic } \\
\text { component }\end{array}$ & $\tau(\mathrm{h})$ & $\begin{array}{l}\text { 2 rhythmic } \\
\text { components }\end{array}$ & $\tau_{1}(\mathrm{~h})$ & $\tau_{2}$ (h) & Full crossover & $\tau$ (h) if no crossover \\
\hline
\end{tabular}

WT/LL

$$
\begin{array}{r}
\quad 500 \\
\text { WT/LL }
\end{array}
$$$$
\left.500 \mu \mathrm{W} / \mathrm{cm}^{2}\right) \quad 16 \quad 16(100 \%)
$$

$$
\left(0.25 \mu \mathrm{W} / \mathrm{cm}^{2}\right)
$$$$
\mathrm{cry}^{b} / \mathrm{LL}
$$$$
\left(500 \mu \mathrm{W} / \mathrm{cm}^{2}\right)
$$$$
\text { cli }^{\text {eya }} ;{ }(\mathrm{ry})^{b} / \mathrm{LL}
$$

$\left(500 \mu \mathrm{W} / \mathrm{cm}^{2}\right)$

WT, Wild-type. 

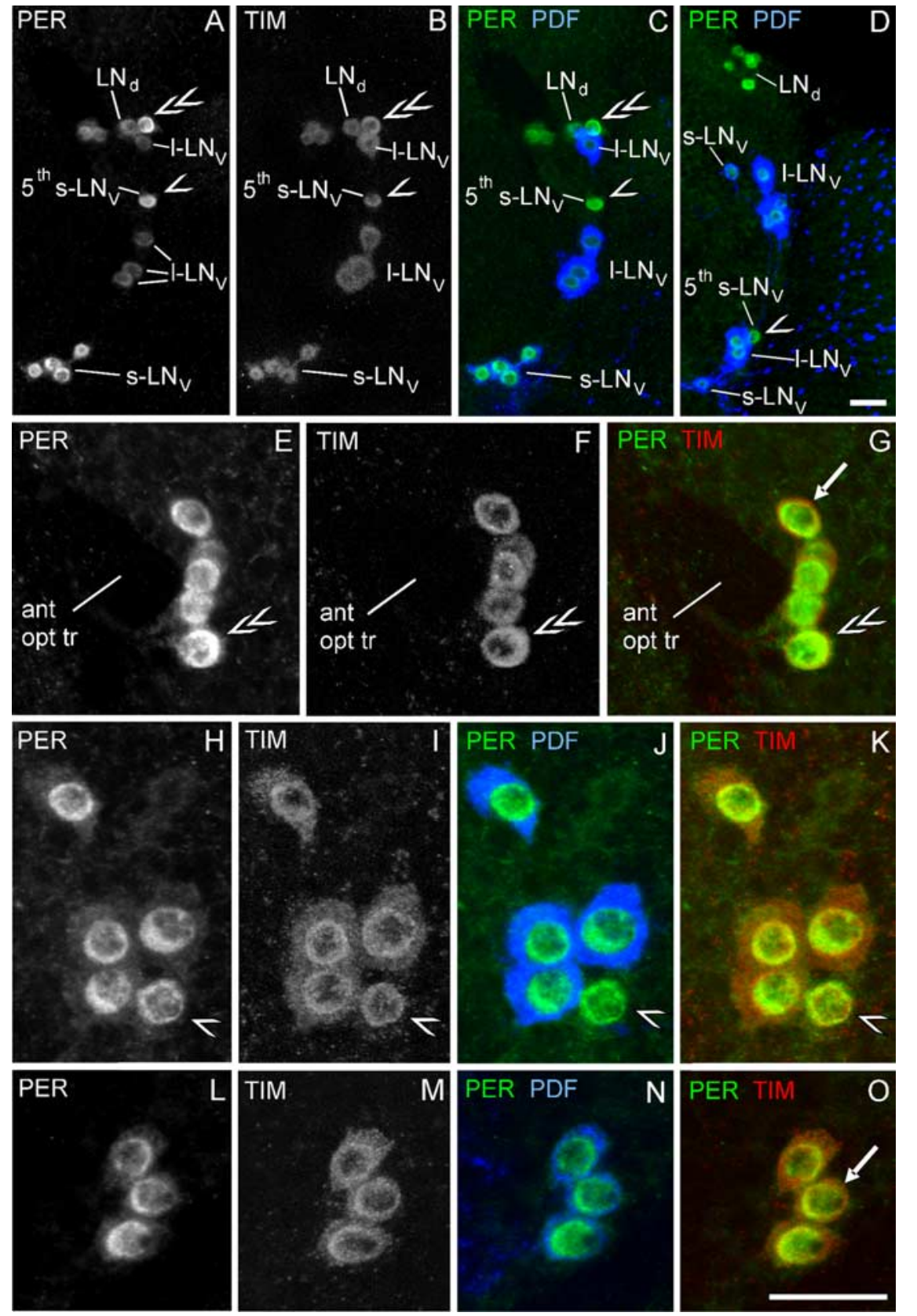

N

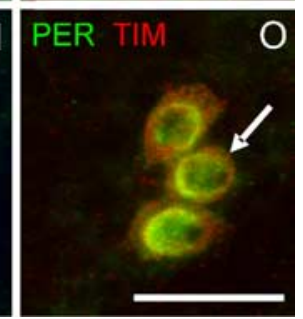

Figure 4. PER, TIM, and PDF expression in the lateral neurons of wild-type flies. For clarity, single labeling is shown in gray, and double labeling is shown in color. $\boldsymbol{A}-\boldsymbol{C}, \boldsymbol{E}-\boldsymbol{G}, \boldsymbol{H}-\boldsymbol{K}$, and $\boldsymbol{L}-\mathbf{O}$ show the same optical sections, respectively. Brains were stained $1 \mathrm{~h}$ before lights on in an LD cycle. At this time point, PER and TIM were predominantly nuclear in all lateral neurons: the $\operatorname{LN}_{d}(\boldsymbol{E}-\boldsymbol{G})$, the $I-\mathrm{LN}_{\mathrm{v}}(\boldsymbol{H}-\boldsymbol{K})$, the 5 th s-LN (arrowhead in $\boldsymbol{A}-\boldsymbol{D}, \boldsymbol{H}-\boldsymbol{K}$ ), and the s-LN $\mathrm{LN}_{\mathrm{v}}(\boldsymbol{L}-\mathbf{0})$. The strongest PER and TIM labeling was found close to the nuclear membrane, whereby TIM was always located slightly lateral of PER (see arrows in $\mathbf{G}$ and $\mathbf{0}$ ). PDF was exclusively found in the cytoplasm of the $\operatorname{l-LN}_{v}(\boldsymbol{J})$ and s- $\mathrm{LN}_{\mathrm{v}}(\boldsymbol{N})$, as well as in their arborizations (e.g., the network on the surface of the medulla in $\left.\boldsymbol{D}\right)$. Note that the nuclei of all groups of lateral neurons were more or less of similar size, but the cytoplasmic area was larger in the I-LN $\mathrm{L}_{v}$. The 5 th PDF-negative - $\mathrm{LN}_{v}$ (arrowhead) could be distinguished from the other cells because it lacked PDF. It was located among the I-LN $(\boldsymbol{A}-\boldsymbol{D}, \boldsymbol{H}-\boldsymbol{K})$. The $\mathrm{LN}_{\mathrm{d}}$ were usually

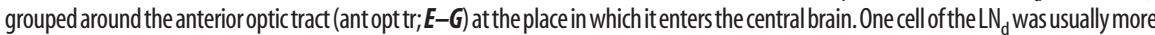
prominently stained than the others and appeared slightly larger (double arrowhead, $\boldsymbol{A}-\boldsymbol{C}, \boldsymbol{E}-\boldsymbol{G}$ ). In the brain shown in $\boldsymbol{D}$, the $\mathrm{LN}_{\mathrm{d}}$ were displaced dorsally toward the $\mathrm{DN}_{3}$ (not in the focal plane). Furthermore, two $\mathrm{I}-\mathrm{LN}_{v}$ and three $s-\mathrm{LN}_{v}$ cells (2 of the latter are below the displaced I-LN $\mathrm{N}_{v}$ and are hard to see) were displaced toward the original location of the $\mathrm{LN}_{\mathrm{d}} \cdot \operatorname{In} \boldsymbol{A}-\mathrm{C}$, one $\mathrm{LNN}_{\mathrm{v}}$ was displaced toward the $\mathrm{LN}_{\mathrm{d}}$. Note that the extra $\mathrm{LN}_{\mathrm{d}}$ (double arrowhead), the 5 th $s-\mathrm{LN}_{\mathrm{v}}$ (arrowhead), and the PDF-positive $-\mathrm{LN}_{\mathrm{v}}$ are the cells that are most prominently stained by anti-PER in $\boldsymbol{A}$. In $\boldsymbol{A}-\boldsymbol{D}, 10$ confocal sections of $5 \mu$ m were combined; $\boldsymbol{E}-\boldsymbol{O}$ consist of five confocal sections of $1 \mu \mathrm{m}$. $\boldsymbol{A}-\boldsymbol{D}$ and $\boldsymbol{E}-\boldsymbol{O}$ are of the same magnification, respectively. Scale bars, $20 \mu \mathrm{m}$.

almost half of the brain hemispheres, at least one l- $\mathrm{LN}_{\mathrm{v}}$ cell was dorsally dislocated and found among the $\mathrm{LN}_{\mathrm{d}}$ (Fig. $4 A-C$, Table 2). In two wild-type brain hemispheres (of different brains), three of four stained l- $\mathrm{LN}_{\mathrm{v}}$ were not only displaced dorsally but addi- tionally posteriorly; these were found on the posterior surface of the brain instead of the anterior surface. In one hemisphere of a $c r y^{b}$ brain, all four $1-\mathrm{LN}_{\mathrm{v}}$ were ventrally displaced. This was the only case in which we found a ventral displacement of the l- $\mathrm{LN}_{\mathrm{v}}$.

The position of the $\mathrm{LN}_{\mathrm{d}}$ was the next most variable. In $20-30 \%$ of the brain hemispheres, they were situated dorsally among the $\mathrm{DN}_{3}$ (Fig. 4D, Table 2). The $s-\mathrm{LN}_{\mathrm{v}}$ held the most constant position, but we still found one to three s- $\mathrm{LN}_{\mathrm{v}}$ cells situated in dorsal position in $5-10 \%$ of the brain hemispheres (Fig. 4D, Table 2). $\chi^{2}$ analysis revealed no significant difference in dislocalized cell groups between wildtype and $c r y^{b}$ flies (Table 2).

In addition to their variable position, we found the $\mathrm{LN}_{\mathrm{d}}$ stained to different degrees by PER and TIM antibodies. In 65\% of the brains, one $\mathrm{LN}_{\mathrm{d}}$ was more strongly stained than the others. This single neuron was characterized by a slightly larger nucleus (Fig. 4E-G) and cytoplasmic area (see Fig. 6) compared with the majority of $\mathrm{LN}_{\mathrm{d}}$ cells. This neuron will be referred to as extra $\mathrm{LN}_{\mathrm{d}}$ cell.

Among the DN cell groups, the two $\mathrm{DN}_{2}$ cells held the most constant position and were easy to identify, because they were always associated with the terminals of the PDF-positive s- $\mathrm{LN}_{\mathrm{v}}$ cells (Fig. 5). The $\mathrm{DN}_{1}$ were more difficult to characterize. These consisted of up to 17 cells that were quite variable in their position; in half of the cases, these were rather clustered, and, in the other half, they were dispersed in the dorsal brain. The staining intensity within the $\mathrm{DN}_{1}$ cells was quite variable. Approximately half of the $\mathrm{DN}_{1}$ cells was strongly stained by anti-PER and anti-TIM, whereas the other half was only weakly labeled (Fig. $5 B, C$ ). Comprising as many as 40 cells, the $\mathrm{DN}_{3}$ cluster was the largest group. The size of the great majority of these neurons was rather small, but, in approximately one-third of the cases, we found up to five larger neurons in a more lateral position (Fig. 5A). These cells were clearly different from dorsally dislocated $\mathrm{LN}_{\mathrm{d}}$ cells.

In summary, we conclude that the $\mathrm{LN}_{\mathrm{d}}$, the $\mathrm{DN}_{1}$, and the $\mathrm{DN}_{3}$ may not represent homogeneous groups of neurons and that this fact has to be taken into account in this study. Similar observations were made in a contemporary study by O. T. Shafer and P. H. Taghert (unpublished observation).

\section{Intracellular location of PER and TIM}

As expected, we found PER and TIM predominantly in the nucleus $1 \mathrm{~h}$ before lights on in LD. These proteins were not uni- 
formly distributed in the nucleus but were restricted to certain compartments, whereby the unmarked regions within the nucleus might correspond to regions of the nucleolus (Fig. 4E-O). The strongest PER immunoreactivity was found at the border of the nucleus close to the nuclear membrane. TIM showed a similar distribution, but the most prominent TIM immunoreactivity was found slightly centrifugal (lateral) of the PER immunoreactivity, suggesting that TIM forms a ring around the nuclear membrane, remaining partly on the cytoplasmic site, whereas PER is mainly located inside the nucleus. This was true for all clock neurons, and it is shown in detail for the three groups of lateral neurons (Fig. 4E-O). PDF remained entirely cytoplasmic and therefore served as good marker for the cytoplasm in the $1-\mathrm{LN}_{\mathrm{v}}$ (Fig. $4 H-K$ ) and s-LN $($ Fig. $4 L-O)$. The $1-\mathrm{LN}_{\mathrm{v}}$ showed a large cytoplasmic area (Fig. $4 \mathrm{~J}$ ), whereas the s- $\mathrm{LN}_{\mathrm{v}}$ contained only small amounts of cytoplasm around the nucleus (Fig. $4 \mathrm{~N}$ ). The cytoplasmic area of the PDF-negative 5 th $\mathrm{s}-\mathrm{LN}_{\mathrm{v}}$, which was always found in vicinity to the $1-\mathrm{LN}_{\mathrm{v}}$, was more difficult to judge, but it seemed similar to that of the $\mathrm{s}-\mathrm{LN}_{\mathrm{v}}$ (Fig. $4 H-K$ ).

\section{Clock protein rhythms in LL}

After ensuring that we could unequivocally identify the different groups of clock neurons, we determined whether the molecular cycling in individual pacemaker neurons becomes internally desynchronized after some days under LL in a manner parallel to the activity rhythm. In contrast to their bimodal activity pattern under LD, wild-type flies have been shown to exhibit a unimodal rhythm in clock protein accumulation. PER and TIM levels are highest $\sim 3 \mathrm{~h}$ before lights on and lowest $12 \mathrm{~h}$ later, as revealed by Western blots on head extracts (Marrus et al., 1996). This means that PER and TIM are at their peak levels at the time of the M activity bout and at trough level at the time of the E activity bout. In the clock neurons, the cycling of PER and/or TIM has been revealed immunohistochemically by several investigators (Zerr et al., 1990; Shafer et al., 2002). These studies revealed no evident phase differences between the diverse neuronal groups. All neurons appear to cycle more or less in-phase and to have the lowest clock protein levels during the flies' main activity peak (the $\mathrm{E}$ activity bout). This appears also true for the $c r y^{b}$ mutants, but only the amplitude of the cycling was reduced in the $\mathrm{LN}_{\mathrm{d}}, 1-\mathrm{LN}_{\mathrm{v}}$, and $\mathrm{DN}_{2}$ cells (Helfrich-Förster et al., 2001; Yoshii et al., 2004). Therefore, we expected all clock neurons to cycle in-phase on the first day in LL, whereas some of them might be out-of-phase several days later under the state of internal desynchronization. This was most easily investigated in $c r y^{b}$ mutants because, in all $c r y^{b}$ flies, the two activity components were in-phase on day 1 and 12 h out-of-phase on day 5 of LL (Fig. 3).

To determine the molecular cycling profiles in the different pacemaker neurons, we performed triple labeling with anti-PER, anti-TIM, and anti-PDF at four critical time points: (1) at the peak and trough of the main activity bout on day 1 when both components were in-phase and (2) at the peak points of both activity components on day 5 when these were $180^{\circ}$ out-of-phase (Fig. 3). In wild-type control flies, PER and TIM levels in the clock neurons were extremely low already on the first day of LL, and no staining at all was found on day 5 (data not shown). This result correlates well with the arrhythmic behavior of the flies under LL conditions at $500 \mu \mathrm{W} / \mathrm{cm}^{2}$. In $c r y^{b}$ mutants, PER and TIM con- tinued to cycle under LL in the s- $\mathrm{LN}_{\mathrm{v}}$ and the $\mathrm{LN}_{\mathrm{d}}$ (Yoshii et al., 2004 and this study). On day 1, we found strong immunostaining at the trough point of the E activity bout and weak immunostaining at its peak point, coinciding nicely with previous results (Yoshii et al., 2004). Highly significant cycling of clock proteins was found in the 5th s- $\mathrm{LN}_{\mathrm{v}}$ cell, the PDF-positive s- $\mathrm{LN}_{\mathrm{v}}$ cells, and the extra $\mathrm{LN}_{\mathrm{d}}$ cell (Fig. 6). The extra $\mathrm{LN}_{\mathrm{d}}$ cell was now discernible as a very prominently stained cell in $95 \%$ of the brains. The clock proteins were nuclear at the trough point of the E activity bout and cytoplasmic at its peak point, showing that they undergo not only a cycling in abundance but also in subcellular location, as shown previously for wild-type flies under constant-dark conditions (Shafer et al., 2002). Some discrepancy occurred in PER and TIM staining levels in the $s-\mathrm{LN}_{\mathrm{v}}$ cells. Although the difference in PER staining at the two time points was highly significant $(p<$ $0.001)$, TIM staining was not significantly different in the $s-\mathrm{LN}_{\mathrm{v}}$ cells. Nevertheless, TIM was nuclear at the time point of high PER staining and cytoplasmic at the time point of low PER staining. Thus, TIM clearly cycled in subcellular location in the PDFpositive s- $\mathrm{LN}_{\mathrm{v}}$ cells. The same was true for the remaining $\mathrm{LN}_{\mathrm{d}}$ and for the $\mathrm{DN}_{2}$. There was a cycling in subcellular location of PER and TIM, but the observed staining differences turned out to be not significant in the post hoc test with Bonferroni's adaptation.

The l- $\mathrm{LN}_{\mathrm{v}}, \mathrm{DN}_{1}$, and $\mathrm{DN}_{3}$ cells showed similar overall staining intensities at both time points. In the $1-\mathrm{LN}_{\mathrm{v}}$, PER was found in the nucleus at both time points, whereas TIM appeared to remain in the cytoplasm (see also below). This suggests that there is no clock protein cycling in the $1-\mathrm{LN}_{\mathrm{v}}$ as was found in wild-type flies under DD conditions (Kaneko et al., 2000; Yang and Sehgal, 2001; Veleri et al., 2003). It should, however, be noted that Peng et al. (2003) found the rhythm in tim mRNA cycling to come back in these neurons after $9 \mathrm{~d}$ in $\mathrm{DD}$. In the $\mathrm{DN}_{1}$ and the $\mathrm{DN}_{3}$, both clock proteins were found in the nucleus in some cells and in the cytoplasm in other cells (Fig. 5C), suggesting that these groups may consist of at least two subclusters of cells that may cycle out-ofphase with each other. Because we had no markers for the different subclusters, it was impossible to unequivocally distinguish the subgroups described above (the different $\mathrm{DN}_{1}$ cells and the laterally located $\mathrm{DN}_{3}$ cells with larger cell bodies).

On day 5 in LL, no cycling of PER and TIM expression were observed for the l- $\mathrm{LN}_{\mathrm{v}}, \mathrm{DN}_{1}$, and $\mathrm{DN}_{3}$. No evident difference in level and location of the clock proteins occurred between the two time points (Fig. 7). The other groups of neurons appeared to maintain a cycling in PER and TIM, which, for the $\mathrm{LN}_{\mathrm{d}}$ and $\mathrm{DN}_{2}$ cells, was again not statistically significant (Fig. 7). Most notably, the phase of the four PDF-positive s-LN $\mathrm{L}_{\mathrm{v}}$ cells was now reversed in respect to the other cycling pacemaker groups. The PDFpositive $s-\mathrm{LN}_{\mathrm{v}}$ cells were strongly stained at the activity peak point of the long-period component (the activity trough of the 

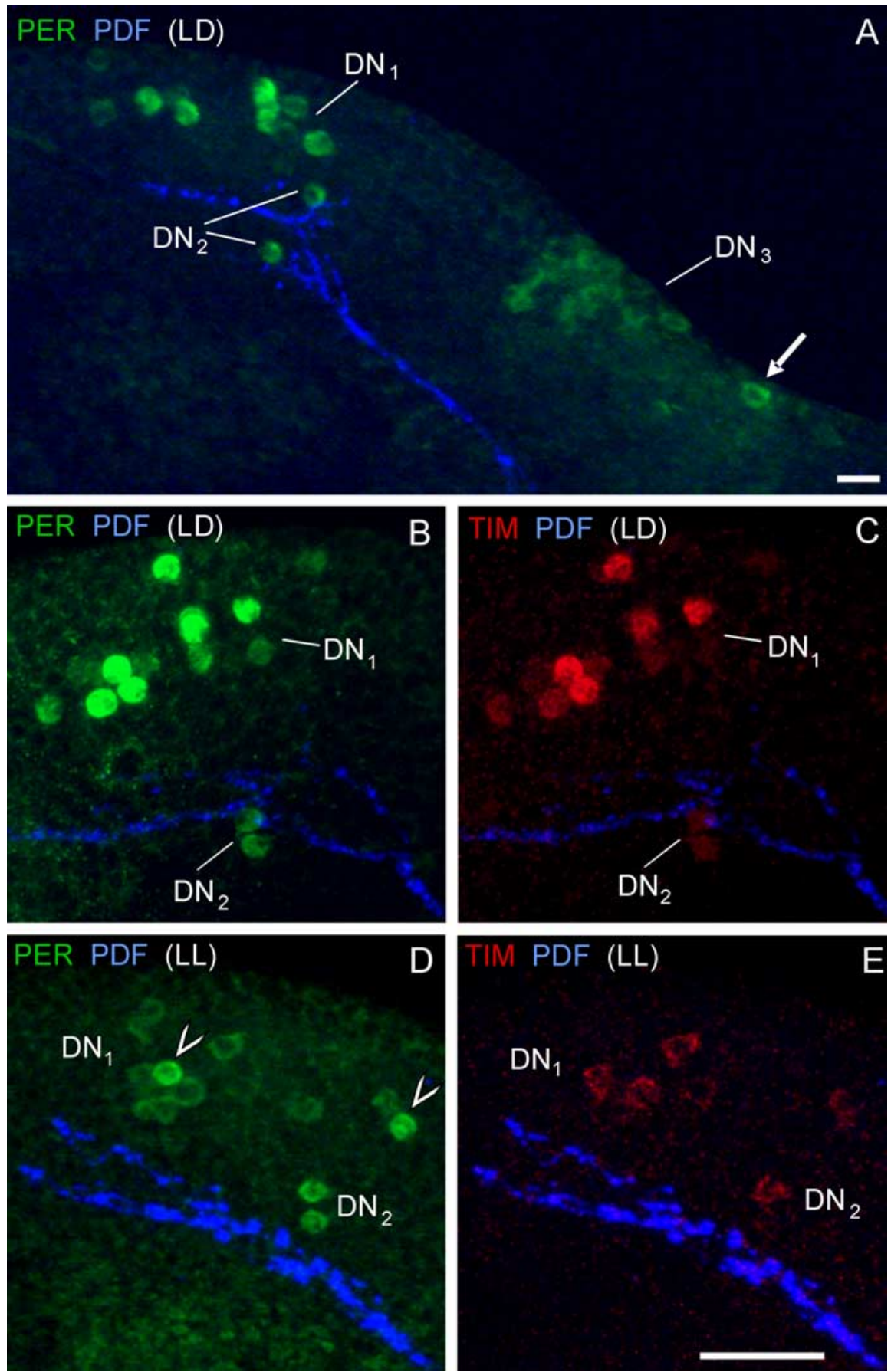

Figure 5. The dorsal neurons of $c r y{ }^{b}$ flies stained with anti-PER (green), anti-TIM (red), and anti-PDF (blue) $1 \mathrm{~h}$ before lights on in an $L D$ cycle $(\boldsymbol{A}-\boldsymbol{C})$ and on the fifth day of $L L$ at time point $C(\boldsymbol{D}, \boldsymbol{E})$. One hour before lights on $(\boldsymbol{A}-\boldsymbol{C})$, PER and TIM were nuclear in most dorsal neurons (the $\mathrm{DN}_{1}, \mathrm{DN}_{2}$, and $\mathrm{DN}_{3}$ cells) except for a few $\mathrm{DN}_{3}$ cells (arrow in $A$ ). The $\mathrm{DN}_{1}$ consisted of up to 17 cells that showed a different intensity of PER and TIM labeling; half of the cells were strongly labeled, and the other half were only weakly labeled $(\boldsymbol{B}, \boldsymbol{C})$. The two $\mathrm{DN}_{2}$ cells were always close to the terminals of the $s-\mathrm{LN}_{\mathrm{v}}$ (blue), and they showed rather weak TIM labeling. On the fifth day of $L L$, TIM labeling was very weak in all dorsal neurons and was restricted to the cytoplasm $(\boldsymbol{D}, \boldsymbol{E})$. PER labeling was nuclear in some DN ${ }_{1}$ cells and cytoplasmic in others. Note that nuclear PER labeling was found in two DN ${ }_{1}$ cells that showed no TIM labeling at all (arrowheads in $\boldsymbol{D}$ ). $\boldsymbol{A}$ consists of 12 confocal sections $(5 \mu \mathrm{m})$. $\boldsymbol{B}$ and $\boldsymbol{C}$ are composed of five confocal sections $(2 \mu \mathrm{m})$ and are of the same magnification. Scale bars, $20 \mu \mathrm{m}$.

short-period component), whereas the other neuronal groups (especially the 5th PDF-negative s-LN $\mathrm{L}_{\mathrm{v}}$ cell and extra $\mathrm{LN}_{\mathrm{d}}$ cell) were maximally stained at the peak point of the short-period component (the activity trough of the long-period component) (Fig. 7). This suggests that the four PDF-positive s- $\mathrm{LN}_{\mathrm{v}}$ cells control the short-period component, whereas the 5th PDF-negative s- $\mathrm{LN}_{\mathrm{v}}$ cell and extra $\mathrm{LN}_{\mathrm{d}}$ cell control the long-period component. Obviously, internal desynchronization has occurred between the PDF-positive $s-\mathrm{LN}_{\mathrm{v}}$ cells and the 5 th s- $\mathrm{LN}_{\mathrm{v}}$ and extra $\mathrm{LN}_{\mathrm{d}}$. Thus, input from the compound eyes seems to shorten the period of the PDF-positive s- $\mathrm{LN}_{\mathrm{v}}$ cells and to lengthen the period of the 5th PDFnegative $s-\mathrm{LN}_{\mathrm{v}}$ and the extra $\mathrm{LN}_{\mathrm{d}}$.

To ensure that the observed internal desynchronization between PDF-positive $s-\mathrm{LN}_{\mathrm{v}}$ and the other two neurons does indeed correlate with the behavioral splitting of $c r y^{b}$ flies and does not generally occur after several days under LL conditions, we stained $c l i{ }^{e y a} ; c^{b} y^{b}$ flies at their E activity peak and trough on day 5. These flies do not show any behavioral desynchronization on day 5 under LL (Fig. $2 E$ ), and, consistent with this behavior, we observed no internal desynchronization between the neuronal groups (Fig. 8). All cell groups were found to be in-phase with each other. Actually, the staining pattern was very similar to $c r y^{b}$ flies on the first day in LL (Fig. 6), with the exception that TIM levels were lower and thus similar to those of $c r y^{b}$ flies on the fifth day in LL (Fig. 7).

To exclude the possibility that the observed internal desynchronization between the neuronal groups is a kind of stationary state in $c r y^{b}$ flies, we also stained flies at two additional time points, just between the activity peaks of both components on day 5 in LL. As expected, we found intermediate staining intensities in all neurons (data not shown), indicating that PER and TIM do indeed cycle in the different neurons. This is consistent with the results of Yoshii et al. (2004), who stained flies every $3 \mathrm{~h}$ throughout day 1 and day 4-5 in LL and additionally on day 9, at which both activity components including both groups of neurons were inphase again.

Although our study is of correlative nature, the results of these experiments further support the model in which behavioral desynchronization is caused by the internal desynchronization between the PDF-positive $\mathrm{s}-\mathrm{LN}_{\mathrm{v}}$ cells and the 5th $s-\mathrm{LN}_{\mathrm{v}}$ and the extra $\mathrm{LN}_{\mathrm{d}}$.

\section{Differences in PER and TIM labeling}

The cycling of both clock proteins appeared to occur principally in parallel, but we observed certain differences in PER and TIM labeling under LL. TIM staining was generally weaker than PER staining (except for the $1-\mathrm{LN}_{\mathrm{v}}$, which showed high cytoplasmic TIM labeling at all time points investigated, but this might be partly attributable to the slight cross-reaction we found for the secondary anti-mouse and anti-rat antibodies and will not be considered further). The low TIM levels are especially evident 
in the dorsal neurons after $5 \mathrm{~d}$ exposure to constant light. TIM was rather weak and mainly cytoplasmic in all three DN clusters (Figs. 5D,E, 7). This suggests that the dorsal neurons possess an additional photopigment that is different from CRY but that may likewise lead to a lightdependent degradation of TIM. The existence of such a still unknown photopigment was predicted by previous studies (Rieger et al., 2003; Veleri et al., 2003). Interestingly, the virtual absence of TIM had little effect on the PER levels in these cells. PER did even continue to move into the nucleus (Fig. 5C). These results corroborate previous studies by Shafer et al. (2002, 2004) showing that PER and TIM do not necessarily have to enter the nucleus together within pacemaker neurons. In support of this contention, we revealed putative phase differences between PER and TIM in the PDF-positive s- $\mathrm{LN}_{\mathrm{v}}$.

Do the PDF-positive s- $\mathrm{LN}_{\mathrm{v}}$ cells compose the $\mathrm{M}$ oscillator and the $\mathrm{LN}_{\mathrm{d}}$ the $\mathrm{E}$ oscillator in the Pittendrigh-Daan model?

Previous studies suggested that the PDFpositive $\mathrm{s}-\mathrm{LN}_{\mathrm{v}}$ control the $\mathrm{M}$ activity bout, whereas the $\mathrm{LN}_{\mathrm{d}}$ govern the $\mathrm{E}$ activity bout (Grima et al., 2004; Stoleru et al., 2004). According to the Pittendrigh-Daan model, the PDF-positive s- $\mathrm{LN}_{\mathrm{v}}$ cells underlie the $\mathrm{M}$ oscillator and should shorten their period under constant-light conditions, whereas the $\mathrm{LN}_{\mathrm{d}}$ underlie the $\mathrm{E}$ oscillator, which lengthens its period under light. For period shortening and lengthening, this is essentially what we observed. However, we found that only one $\mathrm{LN}_{\mathrm{d}}$ (the so-called extra $\mathrm{LN}_{\mathrm{d}}$ ) showed a significant cycling in PER and TIM staining intensity under LL conditions and thus putatively represents an E oscillator. By this same criterion, the 5 th $\mathrm{s}-\mathrm{LN}_{\mathrm{v}}$ cell might be an essential component of the E oscillator. Despite these deviations, our results principally support the hypothesis of Grima et al. (2004) and

Stoleru et al. (2004) that the s- $\mathrm{LN}_{\mathrm{v}}$ and the $\mathrm{LN}_{\mathrm{d}}$ are neuronal substrates of putative $\mathrm{M}$ and $\mathrm{E}$ oscillators in D. melanogaster.

However, unlike Grima et al. (2004) and Stoleru et al. (2004), our behavioral data suggest that the s- $\mathrm{LN}_{\mathrm{v}}$ and the $\mathrm{LN}_{\mathrm{d}}$ cells (the putative $\mathrm{E}$ and $\mathrm{M}$ oscillators) both underlie the evening peak of activity. In the actogram shown in Figure 3, both components started from the E activity bout, whereas the $\mathrm{M}$ activity bout disappeared immediately after transfer into LL. This was typical for most flies. Nevertheless, in 55\% of the flies, we saw an additional weak short-period component running in parallel to the first one (Table 3). This component usually appeared after 1-2 weeks in LL, and it could always be extrapolated back to the M activity bout (Fig. 9A). In rare cases (7.5\%), this short-period component originated directly from the $\mathrm{M}$ activity bout (Table 3). To better judge the behavior of the $\mathrm{M}$ activity bout, we con- ducted an additional experiment, in which we offered 34 flies a weak night light. Light intensity during the night was adjusted to $0.25 \mu \mathrm{W} / \mathrm{cm}^{2}$ (approximate moon light) and was kept at 500 $\mu \mathrm{W} / \mathrm{cm}^{2}$ during the light phase and the following LL, as before. Under these conditions, we could not only see the M activity bout more clearly but we observed the M component of the majority of flies starting to free-run with short period already before transfer into LL (Fig. 9B-D, Table 3). We never found a long-period component originating from the $\mathrm{M}$ activity bout, indicating that the $\mathrm{M}$ oscillator is indeed the one that shortens its period under LL conditions, as predicted by the Pittendrigh-Daan model. However, the putative $\mathrm{M}$ oscillator (the PDF-positive s- $\mathrm{LN}_{\mathrm{v}}$ ) of Drosophila seems to control some aspects of the E activity bout, because a second, and even more pronounced, short-period component detached always from the E activity bout as soon as 


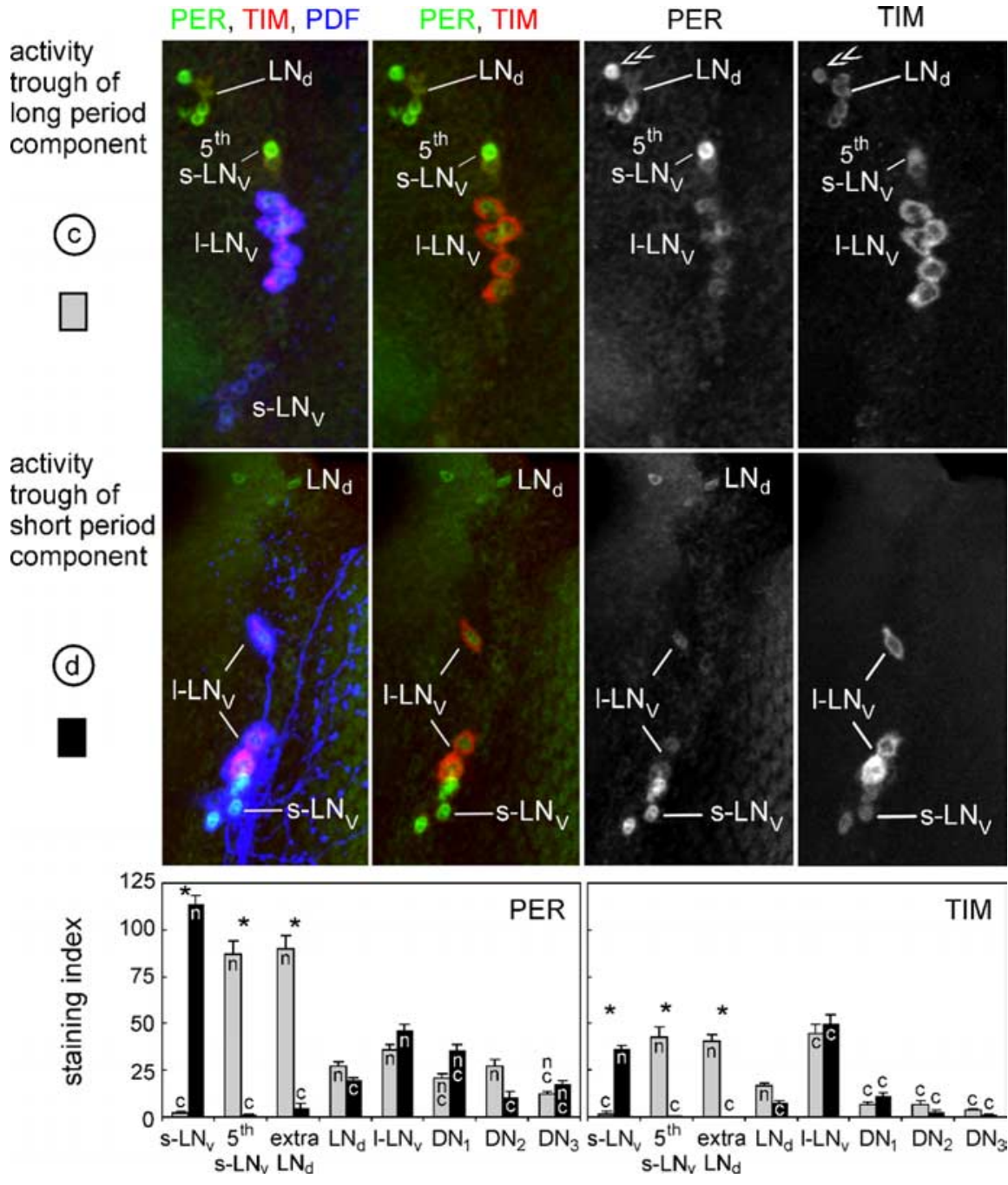

Figure 7. Lateral neurons of internally desynchronized $c r y{ }^{b}$ flies stained on day 5 of $L L$ with anti-PER, anti-TIM, and anti-PDF at the activity trough points of the long-period (time point c) and the short-period (time point d) components (labeling as in Fig. 6). Top, At time point c, strong PER and TIM staining was found in the nuclei of the $\mathrm{LN}_{d}$ cells (especially the extra $\mathrm{LN}_{d}$ cell; double arrowhead) and the PDF-negative 5th s- $\mathrm{LN}_{v}$ cell. Note that the $\mathrm{LN}_{\mathrm{d}}$ cells are differently stained for PER and TIM (details in Results).

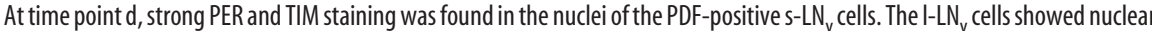
PER and cytoplasmic TIM at both time points (compare with Fig. 6). Bottom, Quantification of the staining intensity for PER and TIM at the time points c and d. Note that staining indices for TIM are rather low, and the protein is mainly cytoplasmic in all three DN groups. Error bars indicate SE.

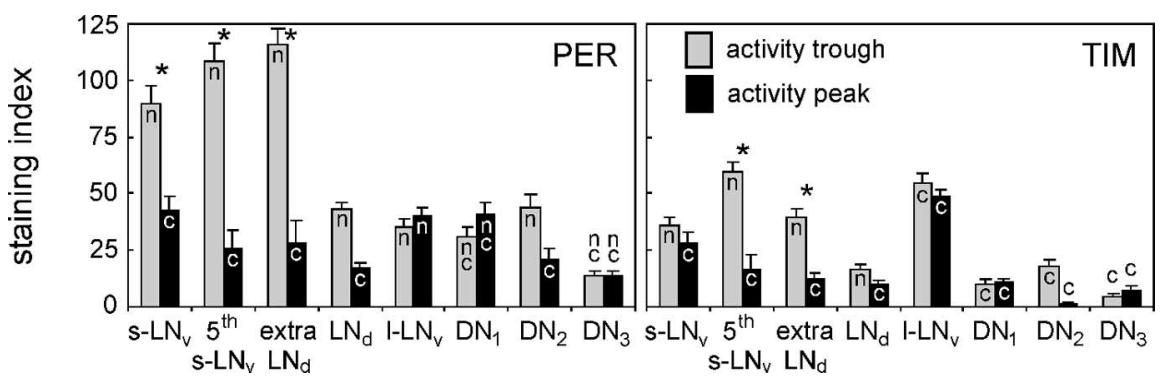

Figure 8. Quantification of the staining intensity for PER and TIM in eyeless cli ${ }^{\text {eya }}$; $\mathrm{cry}^{b}$ flies on the fifth day in $\mathrm{LL}$ at the times of high and low activity (labeling as in Fig. 6). Note that all neurons that show significant differences (asterisks) in staining intensity appear to cycle in-phase. Error bars indicate SE.

the $\mathrm{M}$ activity bout started to free-run (Fig. 9B-D). Thus, the $\mathrm{E}$ activity bout might be controlled by both oscillators (the assumed $\mathrm{M}$ and E cells) and therefore shortens and lengthens its period simultaneously.
If true, the PDF-positive s- $\mathrm{LN}_{\mathrm{v}}$ cells would control $\mathrm{M}$ and $\mathrm{E}$ activity bouts, and the extra $\mathrm{LN}_{\mathrm{d}}$ and the 5 th s- $\mathrm{LN}_{\mathrm{v}}$ cell solely control the evening activity bout (see Discussion). This would introduce an interesting deviation from the original Pittendrigh-Daan model, because we have now no pure M oscillator but rather an "M-E" oscillator that shortens its period during illumination and controls aspects of both the morning and evening bouts of activity. This situation might be special for Drosophila and may account for the very prominent E peak of this species. Despite this deviation, the principle of the Pittendrigh-Daan model still appears valid. One oscillator (the combined M-E oscillator) is shortened by light, and the other (the $\mathrm{E}$ oscillator) is lengthened by light. As a consequence, the activity band would become broader under prolonged light conditions, thus adapting the activity to long summer days.

\section{Discussion}

Role of the PDF-positive s- $\mathrm{LN}_{\mathrm{v}}$ and $\mathrm{LN}_{\mathrm{d}}$ cells in the dual-oscillator system

In this study, we support the notion that the activity rhythm of Drosophila is controlled by at least two sets of neuronal oscillators. Furthermore, we refine the definition of these neuronal substrates of both oscillators more precisely than done before. As proposed by Pittendrigh and Daan (1976), the two oscillators show different responses to light: one is accelerated and the other decelerated by constant light. However, we observed a deviation from the original model. In contrast to previous observations (Grima et al., 2004; Stoleru et al., 2004), our results suggest that the PDF-positive s- $\mathrm{LN}_{\mathrm{v}}$ cells control not only the $\mathrm{M}$ but also the $\mathrm{E}$ activity bout. Therefore, we should perhaps not talk of a "morning" oscillator but rather of an M-E or "main" oscillator (to keep the "M"), for the following reasons. The PDF-positive $s-\mathrm{LN}_{\mathrm{v}}$ cells are essential for maintaining activity rhythms after several days under constant conditions (Renn et al., 1999; Blanchardon et al., 2001; HelfrichFörster et al., 1998; Grima et al., 2004; Stoleru et al., 2004), and electrical silencing of the $\mathrm{LN}_{\mathrm{v}}$ cells severely impairs free-running rhythms (Nitabach et al., 2002). In the present study, the PDFpositive $s-\mathrm{LN}_{\mathrm{v}}$ cells appear to dominate the rhythms in those flies that did couple $\mathrm{E}$ and $\mathrm{M}$ components after the first crossing-over on day 11 in LL, because such flies free-ran with short period (Fig. 9A).

Our hypothesis that the PDF-positive $\mathrm{LN}_{\mathrm{v}}$ cells control not only the $\mathrm{M}$ activity but also partly the $\mathrm{E}$ activity can also explain 
Table 3. Properties of the M component in $\mathrm{cry}^{b}$ mutants under LD, light/moonlight (LM), and LL conditions

\begin{tabular}{|c|c|c|c|c|}
\hline Condition & $n$ & No M activity bout & $\begin{array}{l}\text { M activity bout } \\
\text { entrained }\end{array}$ & $\begin{array}{l}\text { M activity bout free-running } \\
\text { with short period }\end{array}$ \\
\hline LD & 40 & $2(5 \%)$ & $38(95 \%)$ & 0 \\
\hline \multirow[t]{2}{*}{ LM } & 34 & $1(3 \%)$ & $14(41 \%)$ & $19(56 \%)$ \\
\hline & & $\begin{array}{l}\text { No evident short period component } \\
\text { originating from M peak }\end{array}$ & $\begin{array}{l}\text { Short period component can be extrapolated back } \\
\text { to the M peak }\end{array}$ & $\begin{array}{l}\text { Short period component continuing } \\
\text { directly from M peak }\end{array}$ \\
\hline LL (after LD) & 40 & $15(37.5 \%)$ & $22(55 \%)$ & $3(7.5 \%)$ \\
\hline LL (after LM) & 34 & $6(18 \%)$ & $11(32 \%)$ & $18(53 \%)$ \\
\hline
\end{tabular}

other findings. The E activity bout is always the most prominent peak, which persists under constant-dark conditions, whereas the $\mathrm{M}$ activity bout is much reduced under such conditions and may even disappear (Wheeler et al., 1993; Helfrich-Förster, 2000). Thus, mainly the E component constitutes the free-running rhythm, and it seems implausible that the neurons responsible for rhythmicity under these conditions should have no impact on the E component. Indeed, Veleri et al. (2003) found that the $s-\mathrm{LN}_{\mathrm{v}}$ showed the most robust cycling after extended time under constant conditions. Furthermore, during the preparation of this manuscript, a new study by Stoleru et al. (2005) appeared that emphasizes the importance of the $s-\mathrm{LN}_{\mathrm{v}}$ cells for the timing of activity peaks under constant conditions.

Despite their dominance, the PDF-positive s- $\mathrm{LN}_{\mathrm{v}}$ cells depend on functional $\mathrm{LN}_{\mathrm{d}}$ and $\mathrm{DN}$ cells to provoke a normal $\mathrm{E}$ activity bout under light-dark conditions (Grima et al., 2004; Stoleru et al., 2004). Flies with the clock gene PER present only in PDFpositive $\mathrm{LN}_{\mathrm{v}}$ cells have a prominent $\mathrm{M}$ activity bout but lack the $\mathrm{E}$ activity bout (Grima et al., 2004). It is unclear whether this was attributable to the $\mathrm{E}$ activity fusing with the $\mathrm{M}$ activity or whether the E activity is suppressed, but these findings show that the output from the PDF cells requires PER in the $\mathrm{LN}_{\mathrm{d}}$ and DN cells to manifest wild-type activity patterns.

\section{Role of the 5th s-LNv and the DN}

We found that the PDF-negative 5th s- $\mathrm{LN}_{\mathrm{v}}$ cell cycles in-phase with the $\mathrm{LN}_{\mathrm{d}}$ cells under LL and thus may contribute to the $\mathrm{E}$ component. Notably, the PDF-negative 5th $\mathrm{s}-\mathrm{LN}_{\mathrm{v}}$ cell shows high-amplitude cycling (Figs. 6, 7). Although this is not proof of the involvement of this cell, it suggests that it is an important circadian pacemaker neuron. Little is known about this cell because it could not be distinguished from the other lateral neurons in the former studies in which single-labeled clock protein staining was performed (Grima et al., 2004; Stoleru et al., 2004), but the PDF-negative 5th s- $\mathrm{LN}_{\mathrm{v}}$ cell is the only clock cell beside the PDF-positive s- $\mathrm{LN}_{\mathrm{v}}$ cells that appears to work from the first larval instar onward (Kaneko et al., 1997). Thus, it might have the same strong impact on the activity rhythm that was revealed for the PDF-positive s- $\mathrm{LN}_{\mathrm{v}}$ cells (Renn et al., 1999; Blanchardon et al., 2001) (for review, see Helfrich-Förster, 2005). More work is necessary to reveal the role of the PDF-negative s- $\mathrm{LN}_{\mathrm{v}}$ cell in more detail.

Additional studies are also necessary to fully reveal the function of the DN cells. Our results suggest that the $\mathrm{DN}_{1}$ and the $\mathrm{DN}_{3}$ cells may contain different subclusters. Indeed, the $\mathrm{DN}_{1}$ cells develop at different times and appear to have distinct projection patterns (Kaneko et al., 1997; Kaneko and Hall, 2000) (Shafer and Taghert, unpublished observation). It is very likely that some $\mathrm{DN}_{1}$ cells contribute to the $\mathrm{M}$ oscillator whereas others supply the E oscillator. Again, there are data that support this hypothesis: if the lateral neurons $\left(s-\mathrm{LN}_{\mathrm{v}}, 1-\mathrm{LN}_{\mathrm{v}}\right.$, and $\mathrm{LN}_{\mathrm{d}}$ ) are absent as a result of mutation or genetic ablation but the dorsal neurons $\left(\mathrm{DN}_{1}\right.$, $\mathrm{DN}_{2}$, and $\mathrm{DN}_{3}$ ) are left intact, morning and evening activity bouts are still present under LD conditions, although with reduced amplitude and changed phase (Hardin et al., 1992; Helfrich-Förster, 1998; Veleri et al., 2003). The $\mathrm{DN}_{2}$ cells might play a special role for bimodal activity patterns because, in wildtype flies, they cycle $12 \mathrm{~h}$ out-of-phase with the s- $\mathrm{LN}_{\mathrm{v}}$ and $\mathrm{LN}_{\mathrm{d}}$ cells under DD conditions (Veleri et al., 2003). The present study indicates that this is not the case in $c r y^{b}$ flies under LL conditions, because the $\mathrm{DN}_{2}$ cells were in-phase with all other neurons on the first day in LL. The same applies for wild-type flies under LD conditions (Kaneko et al., 1997). In their recent study, Stoleru et al. (2005) showed that the $\mathrm{DN}_{2}$ are indeed pacemaker neurons that cycle independently of the s- $\mathrm{LN}_{\mathrm{v}}$ cells. However, despite their autonomous function, the $\mathrm{DN}_{2}$ cells did not visibly contribute to the activity patterns of the flies under constant darkness. This suggests a minor role of the $\mathrm{DN}_{2}$ cells in the control of the activity rhythm, but we cannot exclude that the $\mathrm{DN}_{2}$, together with the other DN groups, may contribute to morning and evening activity bouts under certain conditions.

\section{Photoreceptors responsible for period shortening and lengthening}

The blue-light photopigment cryptochrome is regarded as the main photoreceptor of the fruit flies' circadian clock (Emery et al., 2000). We show here that the compound eyes are responsible for period shortening and period lengthening of the molecular oscillations in different subsets of pacemaker neurons (the $\mathrm{M}$ and E oscillators) under LL. Their special role may lie in the adaptation of the clock to seasonal changes. This is in line with previous findings showing that the compound eyes are necessary for the adequate timing of $\mathrm{M}$ and $\mathrm{E}$ activity bouts in long summer days and short winter days (Rieger et al., 2003). Cryptochrome, conversely, appears to lengthen the period in all clock neurons as can be deduced from the periods of the wild-type flies that showed internal desynchronization under "moonlight LL." In such flies, the periods of both components were clearly longer than those of internally desynchronized $c r y^{b}$ flies (Table 1).

\section{Dual-oscillator systems}

The internal desynchronization of activity into long- and shortperiod components described here is reminiscent of previous results for Drosophila mutants with primarily reduced optic lobes (Helfrich, 1986) or ectopic expression of PDF (Helfrich-Förster, 2000). Both of these fly strains have ectopic PDF-containing nerve fibers in the dorsal brain that might lead to elevated and/or nonrhythmic secretion of PDF in this brain area and may disturb normal communication between the pacemaker cells. It is unknown whether such a perturbed communication results in internal desynchronization between the s- $\mathrm{LN}_{\mathrm{v}}$ and the 5 th $\mathrm{s}-\mathrm{LN}_{\mathrm{v}}$ and extra $\mathrm{LN}_{\mathrm{d}}$ as observed in the present study. Dual-oscillator 

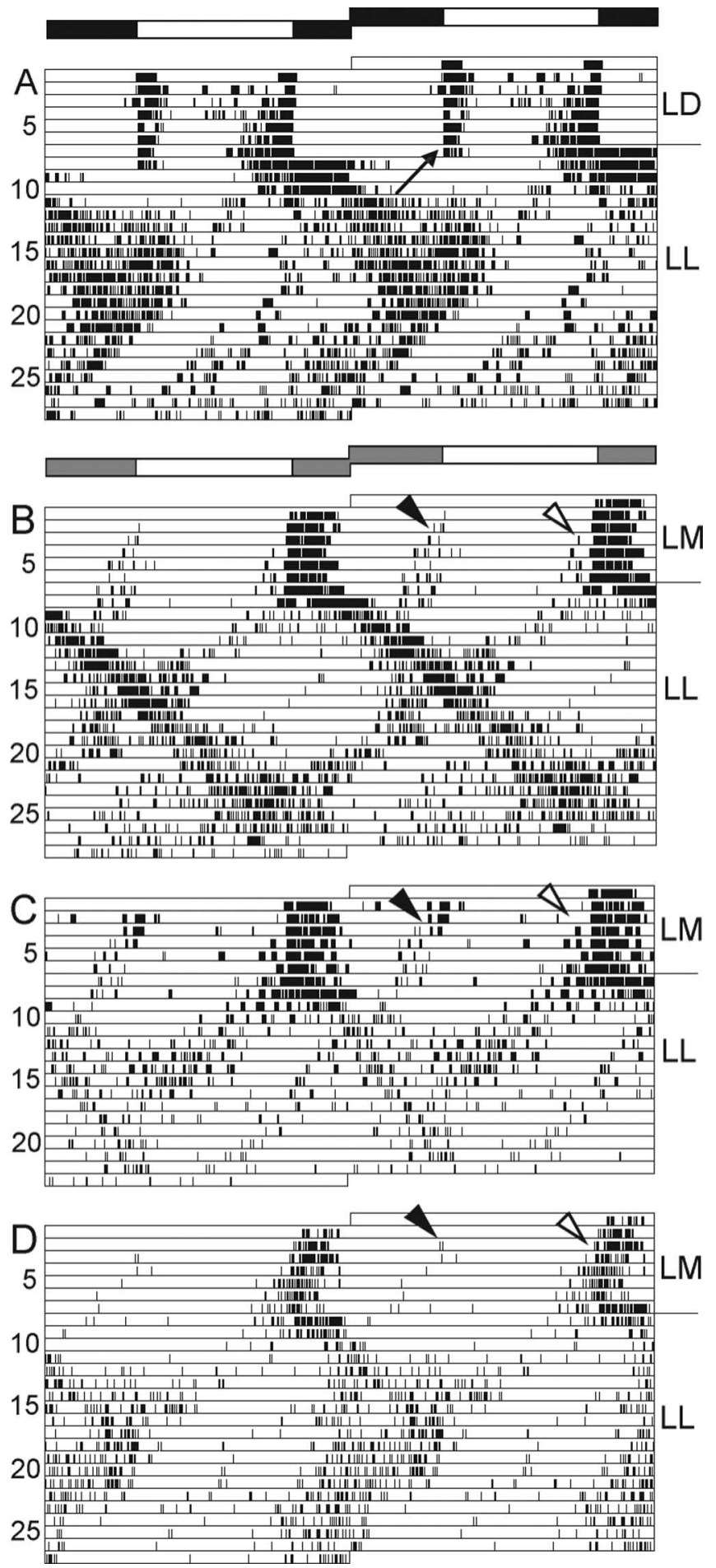

Figure 9. Actograms of $\mathrm{cry}^{b}$ flies showing a short-period component originating from the $\mathrm{M}$ activity bout. The fly shown in $\boldsymbol{A}$ was kept in the usual LD cycle for the first $7 \mathrm{~d}$ and then transferred to $\mathrm{L}$; the other three flies $(\boldsymbol{B}-\boldsymbol{D})$ received dim light during the night and thus had a light/moonlight cycle (LM) (night, gray bars). $A$, A second short-period rhythm appears on day 8 in LL that could be extrapolated back to the morning activity bout (arrow). From day 10 onward in LL, the fly free-ran with the short period. $\boldsymbol{B}-\boldsymbol{D}$, The morning activity bout started to free-run with a short period already during the LM cycle (filled arrowhead). At the same time, a short-period component also detached from the E activity bout (open arrowhead). In LL, the short-period components originating from the $\mathrm{M}$ and $\mathrm{E}$ activity bouts continued to free-run, indicating that the neurons free-running with short period under $L \mathrm{~L}$ control $\mathrm{M}$ and $\mathrm{E}$ activity bouts simultaneously. systems have been also described for mammals, but in no case they could be traced to the level of single neurons (Shinohara et al., 1995; Jagota et al., 2000; de la Iglesia et al., 2004). Like the circadian pacemaker center of flies, the mammalian pacemaker center, the suprachiasmatic nucleus (SCN), contains a heterogeneous neuronal population (Lee et al., 2003). A recent study has shown that internal desynchronization of motor activity into short and long periods similar to the one shown here can be provoked in rats by special light schedules (de la Iglesia et al., 2004). Like in Drosophila, both components reflect the separate activities of two oscillators in anatomically defined subdivisions of the SCN. Furthermore, there is some evidence to suggest that the SCN is composed of two oscillating $\mathrm{M}$ and $\mathrm{E}$ components (Jagota et al., 2000). These results underline the universality of dual-oscillator systems.

The work of Grima et al. (2004) and Stoleru et al. (2004) strongly implicated the PDF-expressing $\mathrm{LN}_{\mathrm{v}}$ and the $\mathrm{LN}_{\mathrm{d}}$ cells as the respective neuronal loci for the morning and evening activity bouts. Despite the near $12 \mathrm{~h}$ phase difference between the morning and evening locomotor peaks under LD, no obvious molecular phase differences between these pacemakers have been observed that would explain them (Grima et al., 2004). Work in mammals suggests that the relationship between molecular phase and locomotion is complex. For example, nocturnal and diurnal rodents show the same phases of PER oscillations (Smale et al., 2003). Furthermore, different rat strains that displayed unimodal or multimodal activity patterns, respectively, all exhibited the same unimodal rhythm in melatonin synthesis (Klante et al., 1999). Individual Nile grass rats changed their activity patterns from unimodal-diurnal to bimodal-nocturnal after introducing a running wheel (Blanchong et al., 1999). Despite this dramatic effect on the activity patterns, the wheel had little effect on the circadian pacemaker, and the spatial and temporal patterns of c-Fos expression in the SCN remained similar (Smale et al., 2003). All of these data indicate that the relationship between molecular and behavioral phase is not straightforward. Clearly, a multitude of phase relationships between the molecular rhythm and behavior are possible. Brain regions outside the pacemaker center may be responsible for these different phases as was shown recently for mammals (Nixon and Smale, 2004; Schwartz et al., 2004; Saper et al., 2005; Schwartz and Smale, 2005). It appears that the same is true within the circadian system of the fly. The present data as well as previous data (Yoshii et al., 2004) show that, during the internally synchronized state, the trough in PER level of all neurons correlates with the main activity bout (the $\mathrm{E}$ peak). No second trough appears to correlate with the M peak. However, a second small peak can be seen at closer inspection of the PDF immunoreactivity in the terminals of the s- $\mathrm{LN}_{\mathrm{v}}$ (Park et al., 2000, their Fig. 4). This suggests that the unimodal rhythm in clock protein cycling might be converted into a bimodal output already within the neurons. We admit, however, that the bimodality in PDF cycling was not stated in this paper and that additional experiments are necessary to confirm it.

During the state of behavioral desynchronization under LL conditions, we observed simultaneously an internal desynchronization in PER oscillations among subsets of pacemaker neurons. One interpretation of our data is that constant light causes internal desynchronization between these pacemaker neurons that then in turn drive the behavioral outputs. However, it must be acknowledged that this is only a correlation, and, although we favor the hypothesis that the split molecular rhythms are driving the split locomotor rhythms, it is possible that they are merely tracking or entraining to a split rhythm driven by other pacemak- 
ers. For example, the split rhythms might be driven by subsets of dorsal neurons. We prefer the hypothesis that the split behavioral rhythms were driven by the desynchronized PDF-positive $\mathrm{LN}_{\mathrm{v}}$ and the 5 th s- $\mathrm{LN}_{\mathrm{v}}$ /extra $\mathrm{LN}_{\mathrm{d}}$ cells for two reasons. First, accumulating evidence points to the lateral neurons $\left(\mathrm{LN}_{\mathrm{v}}\right.$ and $\mathrm{LN}_{\mathrm{d}}$ cells) as major pacemaker cells, whereas the dorsal neurons (the $\mathrm{DN}_{1}$, $\mathrm{DN}_{2}$, and $\mathrm{DN}_{3}$ cells) are not sufficient for locomotor rhythms under constant darkness (for review, see Hall, 2005; HelfrichFörster, 2005). Second, in rodents, a similar behavioral desynchronization was correlated with a dissociation of clock gene expression between ventrolateral and dorsomedial subdivisions of the SCN (de la Iglesia et al., 2004). The established role of this brain center as the circadian clock led to the uncontroversial conclusion that the split molecular oscillations were driving the split behavioral oscillations. We suggest that the same phenomenon is occurring in main (i.e., small $\mathrm{LN}_{\mathrm{v}}$ cells) and evening (i.e., 5th s- $\mathrm{LN}_{\mathrm{v}}$ and extra $\mathrm{LN}_{\mathrm{d}}$ cells) neuronal oscillators in Drosophila.

\section{References}

Aschoff J (1966) Circadian activity pattern with two peaks. Ecology $47: 657-662$.

Aschoff J (1979) Circadian rhythms: influences of internal and external factors on the period measured in constant conditions. Z Tierpsychol 49:225-249.

Blanchardon E, Grima EB, Klarsfeld A, Chelot E, Hardin PE, Preat T, Rouyer F (2001) Defining the role of Drosophila lateral neurons in the control of activity and eclosion rhythms by targeted genetic ablation and PERIOD overexpression. Eur J Neurosci 13:871-888.

Blanchong JA, McElhinny, Mahoney MM, Smale L (1999) Nocturnal and diurnal rhythms in the unstriped nile rat, Arvicanthis niloticus. J Biol Rhythms 14:364-377.

Busza A, Emery-Le M, Rosbash M, Emery P (2004) Roles of the two CRYPTOCHROME structural domains in circadian photoreception. Science 304:1503-1506.

Ceriani MF, Darlington TK, Staknis D, Mas P, Petti AA, Weitz CJ, Kay SA (1999) Light-dependent sequestration of TIMELESS by CRYPTOCHROME. Science 285:553-556.

Daan S, Albrecht U, van der Horst GTJ, Illnerová H, Roenneberg T, Wehr TA, Schwartz WJ (2001) Assembling a clock for all seasons: are there M and E oscillators in the genes? J Biol Rhythms 16:105-116.

de la Iglesia HO, Meyer J, Schwartz WJ (2004) Forced desynchronization of dual circadian oscillators within the rat suprachiasmatic nucleus. Curr Biol 14:796-800.

Dunlap J, Loros J, DeCoursey PJ (2003) Chronobiology: biological timekeeping. Sunderland, MA: Sinauer.

Emery P, Stanewsky R, Hall JC, Rosbash M (2000) Drosophila cryptochrome: a unique circadian-rhythm photoreceptor. Nature 404:456-457.

Grima B, Chélot E, Xia R, Rouyer F (2004) Morning and evening peaks of activity are controlled by different clock neurons of the Drosophila brain. Nature 431:869-873.

Hall JC (2005) Systems approaches to biological rhythms in Drosophila. Methods Enzymol 393:161-185.

Hardin PE (2004) Transcription regulation within the circadian clock: the E-box and beyond. J Biol Rhythms 19:348-360.

Hardin PE, Hall JC, Rosbash M (1992) Behavioral and molecular analyses suggest that circadian output is disrupted by disconnected mutants in $D$. melanogaster. EMBO J 11:1-6.

Helfrich C (1986) Role of the optic lobes in the regulation of the locomotor activity of Drosophila melanogaster: behavioral analysis of neural mutants. J Neurogenet 3:321-343.

Helfrich-Förster C (1995) The period clock gene is expressed in CNS neurons, which also produce a neuropeptide that reveals the projections of circadian pacemaker cells within the brain of Drosophila melanogaster. Proc Natl Acad Sci USA 92:612-616.

Helfrich-Förster C (1998) Robust circadian rhythmicity of Drosophila melanogaster requires the presence of lateral neurons: a brain-behavioral study of disconnected mutants. J Comp Physiol A Neuroethol Sens Neural Behav Physiol 182:435-453.
Helfrich-Förster C (2000) Differential control of morning and evening components in the activity rhythm of Drosophila melanogaster: sex specific differences suggest a different quality of activity. J Biol Rhythms 15:135-154.

Helfrich-Förster C (2001) The activity rhythm of Drosophila melanogaster is controlled by a dual oscillator system. J Insect Physiol 47:877-887.

Helfrich-Förster C (2004) The circadian clock in the brain: a structural and functional comparison between mammals and insects. J Comp Physiol A Neuroethol Sens Neural Behav Physiol 190:601-613.

Helfrich-Förster C (2005) Neurobiology of the fruit fly's circadian clock. Genes Brain Behav 4:65-76.

Helfrich-Förster C, Winter C, Hofbauer A, Hall JC, Stanewsky R (2001) The circadian clock of fruit flies is blind after elimination of all known photoreceptors. Neuron 30:249-261.

Jagota A, de la Iglesia HO, Schwartz WJ (2000) Morning and evening circadian oscillations in the suprachiasmatic nucleus in vitro. Nat Neurosci 3:372-376.

Kaneko M, Hall JC (2000) Neuroanatomy of cells expressing clock genes in Drosophila: transgenic manipulation of the period and timeless genes to mark the perikarya of circadian pacemaker neurons and their projections. J Comp Neurol 422:66-94.

Kaneko M, Helfrich-Förster C, Hall JC (1997) Spatial and temporal expression of the period and timeless genes in the developing nervous system of Drosophila: newly identified pacemaker candidates and novel features of clock gene product cycling. J Neurosci 17:6745-6760.

Kaneko M, Park JH, Cheng Y, Hardin PE, Hall JC (2000) Disruption of synaptic transmission or clock-gene-product oscillations in circadian pacemaker cells of Drosophila cause abnormal behavioural rhythms. J Neurobiol 43:207-233.

Klante G, Secci K, Masson-Pévet M, Pévet P, Vivien-Roels B, Steinlechner S, Wollnik F (1999) Interstrain differences in activity pattern, pineal function, and SCN melatonin receptor density of rats. Am J Physiol 276:R1078-R1086.

Konopka RJ, Pittendrigh C, Orr D (1989) Reciprocal behaviour associated with altered homeostasis and photosensitivity of Drosophila clock mutants. J Neurogenet 6:1-10.

Lee HS, Billings HJ, Lehman MN (2003) The suprachiasmatic nucleus: a clock of multiple components. J Biol Rhythms 18:435-449.

Majercak J, Sidote D, Hardin PE, Edery I (1999) How a circadian clock adapts to seasonal decreases in temperature and day length. Neuron 24:219-230.

Marrus SB, Zheng H, Rosbash M (1996) Effect of constant light and circadian entrainment of perS flies: evidence for light-mediated delay of the negative feedback loop in Drosophila. EMBO J 15:6877-6886.

Nitabach MN, Blau J, Holmes TC (2002) Electrical silencing of Drosophila pacemaker neurons stops the free-running circadian clock. Cell 109:485-495.

Nitabach MN, Sheeba V, Vera DA, Blau J, Holmes TC (2005) Membrane electrical excitability is necessary for the free-running larval Drosophila circadian clock. J Neurobiol 62:1-13.

Nixon JP, Smale L (2004) Individual differences in wheel-running rhythms are related to temporal and spatial patterns of activation of Orexin A and $\mathrm{B}$ cells in a diurnal rodent (Arvicanthis niloticus). Neuroscience 127:25-34.

Park JH, Helfrich-Förster C, Lee G, Liu L, Rosbash M, Hall JC (2000) Differential regulation of circadian pacemaker output by separate clock genes in Drosophila. Proc Natl Acad Sci USA 97:3608-3613.

Peng Y, Stoleru D, Levine JD, Hall JC, Rosbash M (2003) Drosophila freerunning rhythms require intercellular communication. PLoS Biol 1:E13.

Pittendrigh CS, Daan S (1976) A functional analysis of circadian pacemakers in nocturnal rodents. V. Pacemaker structure: a clock for all seasons. J Comp Physiol A Neuroethol Sens Neural Behav Physiol 106:333-355.

Renn SCP, Park JH, Rosbash M, Hall JC, Taghert PH (1999) A pdf neuropeptide gene mutation and ablation of PDF neurons each cause severe abnormalities of behavioral circadian rhythms in Drosophila. Cell 99:791-802.

Rieger D, Stanewsky R, Helfrich-Förster C (2003) Cryptochrome, compound eyes, Hofbauer-Buchner eyelets, and ocelli play different roles in the entrainment and masking pathway of the locomotor activity rhythm in the fruit fly Drosophila melanogaster. J Biol Rhythms 18:377-391.

Rosato E, Codd V, Mazzotta G, Piccin A, Zordan M, Costa R, Kyriacou CP 
(2001) Light-dependent interaction between Drosophila CRY and the clock protein PER mediated by the carboxy terminus of CRY. Curr Biol 11:909-917.

Saper CB, Lu J, Chou TC, Gooley J (2005) The hypothalamic integrator for circadian rhythms. Trends Neurosci 28:152-157.

Schwartz WJ (2004) Sunrise and sunset in fly brains. Nature 431:751-752.

Schwartz MD, Smale L (2005) Individual differences in rhythms of behavioral sleep and its neural substrates in Nile grass rats. J Biol Rhythms 20:526-537.

Schwartz MD, Nunez AA, Smale L (2004) Differences in the suprachiasmatic nucleus and lower subparaventricular zone of diurnal and nocturnal rodents. Neuroscience 127:13-23.

Shafer OT, Rosbash M, Truman JW (2002) Sequential nuclear accumulation of the clock proteins period and timeless in the pacemaker neurons of Drosophila melanogaster. J Neurosci 22:5946-5954.

Shafer OT, Levine JD, Truman JW, Hall JC (2004) Flies by night: effects of changing day length on Drosophila's circadian clock. Curr Biol 14:424-432.

Shinohara K, Honma S, Katsuno Y, Abe H, Honma K (1995) Two distinct oscillators in the rat suprachiasmatic nucleus in vitro. Proc Natl Acad Sci USA 92:7396-7400.

Smale L, Lee T, Nunez AA (2003) Mammalian diurnality: some facts and gaps. J Biol Rhythms 18:356-366.

Stanewsky R, Frisch B, Brandes C, Hamblen-Coyle MJ, Rosbash M, Hall JC (1997) Temporal and spatial expression patterns of transgenes containing increasing amounts of the Drosophila clock gene period and a lacZ reporter: mapping elements of the PER protein involved in circadian cycling. J Neurosci 17:676-696.

Stanewsky R, Kaneko M, Emery P, Beretta B, Wager-Smith K, Kay SA, Rosbash M, Hall JC (1998) The $c r y^{b}$ mutation identifies cryptochrome as a circadian photoreceptor in Drosophila. Cell 95:681-692.

Stoleru D, Peng Y, Agosto J, Rosbash M (2004) Coupled oscillators control morning and evening locomotor behavior of Drosophila. Nature 431:862-868.

Stoleru D, Peng Y, Nawathean P, Rosbash M (2005) A resetting signal between Drosophila pacemakers synchronizes morning and evening activity. Nature 438:238-242.

Veleri S, Brandes C, Helfrich-Förster C, Hall JC, Stanewsky R (2003) A selfsustaining, light-entrainable circadian oscillator in the Drosophila brain. Curr Biol 13:1758-1767.

Wheeler DA, Hamblen-Coyle MJ, Dushay MS, Hall JC (1993) Behav in light-dark cycles of Drosophila mutants that are blind, arrhythmic, or both. J Biol Rhythms 8:67-94.

Yang Z, Sehgal A (2001) Role of molecular oscillations in generating behavioral rhythms in Drosophila. Neuron 29:453-467.

Yoshii T, Funada Y, Ibuki-Ishibashi T, Matsumoto A, Tanimura T, Tomioka K (2004) Drosophila cry ${ }^{\mathrm{b}}$ mutation reveals two circadian clocks that drive locomotor rhythm and have different responsiveness to light. J Insect Physiol 50:479-488.

Zerr DM, Hall JC, Rosbash M, Siwicki KK (1990) Circadian fluctuations of period protein immunoreactivity in the CNS and the visual system of Drosophila. J Neurosci 10:2749-2762. 